\title{
Erratum to: Host discrimination ability in the tephritid parasitoid Psyttalia concolor (Hymenoptera: Braconidae)
}

\author{
Giovanni Benelli • Gabriele Gennari • \\ Angelo Canale
}

Published online: 5 June 2013

(c) Springer-Verlag Berlin Heidelberg 2013

\section{Erratum to: J Pest Sci (2013) 86:245-251 \\ DOI 10.1007/s10340-012-0471-9}

Unfortunately there were some errors in the reference of the original publication. The genus name and the species name were printed as "Dendroceruscarpenteri" instead of "Dendrocerus carpenteri", "Microplitisrufiventris" instead of "Microplitis rufiventris", "Spodopteralittoralis" instead of "Spodoptera littoralis", "Trissolcusnigripedius" instead of "Trissolcus nigripedius", "Telenomusgifuensis" instead of "Telenomus gifuensis", "Dolycorisbaccarum" instead of "Dolycoris baccarum", "Anaphesnitens" instead of "Anaphes nitens", "Gonipterusscutellatus" instead of "Gonipterus scutellatus", "Monodontomerusobsoletus" instead of "Monodontomerus obsoletus", "Megachilerotundata" instead of "Megachile rotundata", "Trichogrammaevanescens" instead of "Trichogramma evanescens", "Spathiusagrili" instead of "Spathius agrili", "Haplogonatopusatratus" instead of "Haplogonatopus atratus", "Campoletischloridae" instead of "Campoletis chloridae" and "Mythimnaseparata" instead of "Mythimna separata". The authors apologize to the readers and state they are not responsible for the mentioned errors.
The online version of the original article can be found under doi: 10.1007/s10340-012-0471-9.

G. Benelli · G. Gennari · A. Canale ( $₫)$

Department of Agriculture, Food and Environment,

University of Pisa, Via San Michele degli Scalzi 2,

56124 Pisa, Italy

e-mail: acanale@agr.unipi.it 